\title{
Microdetermination of Methenamine in the Presence of Formaldehyde by Solid Phase Spectrophotometry
}

\author{
Mehdi Taghdiri, ${ }^{1}$ Yadollah Yamini, ${ }^{2}$ and Ali Moloudi ${ }^{1}$ \\ ${ }^{1}$ Department of Chemistry, Payame Noor University, P.O. Box 19395-3697, Tehran, Iran \\ ${ }^{2}$ Department of Chemistry, Tarbiat Modares University, P.O. Box 14115-175, Tehran, Iran \\ Correspondence should be addressed to Mehdi Taghdiri, mehditaghdiri@yahoo.com
}

Received 23 October 2012; Accepted 11 November 2012

Academic Editors: R. Fausto, S.-Y. Lin, and M. Mạczka

Copyright ( 12012 Mehdi Taghdiri et al. This is an open access article distributed under the Creative Commons Attribution License, which permits unrestricted use, distribution, and reproduction in any medium, provided the original work is properly cited.

\begin{abstract}
A sensitive spectrophotometric method for the determination of methenamine has been developed without any separation steps. Bromocresol green is adsorbed on Sephadex LH-20 gel but the sorption decreases in the presence of methenamine due to ion-pair formation between bromocresol green and methenamine in solution. This attenuation was used to the microdetermination of methenamine by measurement of absorbance of the solid phase (Sephadex LH-20 gel) in a $1.0 \mathrm{~mm}$ cell at $625 \mathrm{~nm}$. Methenamine could be determined in the concentration range of $0.42-1.68 \mu \mathrm{g} \mathrm{mL}^{-1}(10-\mathrm{mL}$ Sample volume) with a relative standard deviation (RSD) of $0.03 \%(n=4)$. The detection limit obtained was $50 \mu \mathrm{g} \mathrm{L}{ }^{-1}$ for $10 \mathrm{~mL}$ sample volume. The method was used for determination of methenamine in industrial wastewater and a satisfactory result was obtained.
\end{abstract}

\section{Introduction}

Methenamine (MT), $\left(\mathrm{CH}_{2}\right)_{6} \mathrm{~N}_{4}$, also known as 1,3,5,7-tetraazatricyclo[3.3.1.1. $\left.{ }^{3,7}\right]$ decane, urotropine, hexamine, hexamethylenetetramine, formin, and aminoform (Figure 1), is a relatively old common urinary tract antiseptic [1]. It is also used for the production of plastic materials, explosives, phenolic resins, antibacterial pharmaceutics, disinfecting materials, in the rubber industry as an additive, and so forth [2]. The most common production method of MT in industrial scale is the reaction of formaldehyde with ammonia or ammonium salts $[3,4]$. Methenamine wastewater that is formed in the production of MT usually contains residual amounts of MT and formaldehyde [5].

Many methods have been developed for the determination of milligram amounts of MT; these methods have been cited by Madsen et al. [6]. However, there are relatively few methods available for the determination of MT at microgram levels [6-8].

Determination of MT in the presence of formaldehyde and ammonia is difficult because most of methods are indirect determinations based on the determination of the amount of formaldehyde released after hydrolysis of MT in acidic condition [6]. Therefore, in order to determine the amount of formaldehyde formed from the hydrolysis of MT, the amount of formaldehyde originally present must be determined prior to hydrolysis and then subtracted from the amount of formaldehyde formed after hydrolysis.

HPLC and GC methods have been described for the determination of MT with expensive apparatus that use organic solvents $[7,8]$. The spectrophotometry has been also used for determination of MT with the use of organic compounds that react with MT [1, 9-13].

This study presents a sensitive Solid Phase Spectrophotometry (SPS) method for the direct determination of microgram amounts of MT in pure aqueous solutions in the presence of formaldehyde. The determination of MT was carried out with inhibition of the sorption of bromocresol green (BCG) on a solid phase from an aqueous solution, and the subsequent measurement of absorption, directly in the solid phase. SPS in visible region has been less used for determination of organic compounds [14]. We present an innovative work to use SPS in visible region for determination of MT. A higher molar absorptivity was obtained by this proposed method than other spectrophotometric methods. 


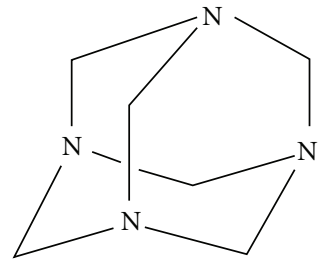

FIgURE 1: The molecular structure of methenamine.

Methenamine forms an ion-pair with BCG in solution and therefore, the sorption of BCG on the solid phase decreases. We used the Sephadex LH-20 as solid phase. Sephadex LH-20 medium is based on hydroxypropylated dextran that has been cross-linked to yield a polysaccharide network [15].

\section{Experimental}

2.1. Materials and Solutions. Citric acid, sodium hydroxide, potassium hydroxide, sodium acetate, acetic acid, and bromocresol green (all from Merck) were of the highest purity available and used as received. The methenamine powder (99.5\%) was from Sina Chemical Industries Co. (Iran). It was recrystallized from ethanol and dried at $60^{\circ} \mathrm{C}$ to constant weight and used for preparation of standard solutions of MT.

The Sephadex LH-20 gel (mesh 25-100 mm) (Aldrich) in its original dry state without pretreatment was used as solid support.

The stock solution was prepared by dissolving an appropriate amount of MT in water to obtain a concentration of $3.0 \times 10^{-4} \mathrm{M}$. Citrate buffer, $\mathrm{pH} 4.0$, was prepared by titrating aqueous $0.1 \mathrm{M}$ disodium citrate $(19.2 \mathrm{~g}$ citric acid $+200 \mathrm{~mL}$ of $1 \mathrm{M} \mathrm{NaOH} / 1000 \mathrm{~mL} \mathrm{H}_{2} \mathrm{O}$ ) with $0.1 \mathrm{M} \mathrm{HCl}$. Bromocresol green was dissolved in $4.0 \times 10^{-4} \mathrm{M} \mathrm{NaOH}$ and was diluted to $100.0 \mathrm{~mL}$ with the $\mathrm{pH} 4.0$ citrate buffer to produce a $1.0 \times 10^{-4} \mathrm{M}$ solution. Buffer solutions and bromocresol green stock solutions were adjusted to an ionic strength of 0.2 with $\mathrm{KCl}$. Wastewater sample was obtained from Sina Chemical Industries Co.

2.2. Apparatus. Weighing of materials was performed by using an analytical balance model Sartorius MCBA 100 with precision of $\pm 0.0001 \mathrm{~g}$. $\mathrm{pH}$ measurements were carried out with a Metrohm $691 \mathrm{pH}$-meter. A GBC spectrophotometer model Cintra 6 was used for spectrophotometric measurements.

2.3. Procedures. A $10-\mathrm{mL}$ sample containing 0.42 $1.68 \mu \mathrm{g} \mathrm{mL}^{-1}$ of MT was transferred to a $100 \mathrm{~mL}$ Beaker and then $4 \mathrm{~mL}$ of $1.0 \times 10^{-4} \mathrm{M}$ BCG was added. The mixture was stirred mechanically for $4 \mathrm{~min}$. Then $70 \mathrm{mg}$ of Sephadex LH-20 (25-100 mesh) gel was added and the mixture was stirred mechanically for $5 \mathrm{~min}$ and the coloured gel was collected by centrifuge and, using a little pipette, packed into a $1 \mathrm{~mm}$ cell together with a small volume of the filtrate. The cell was centrifuged at $2500 \mathrm{rpm}$ for $1 \mathrm{~min}$. A blank solution

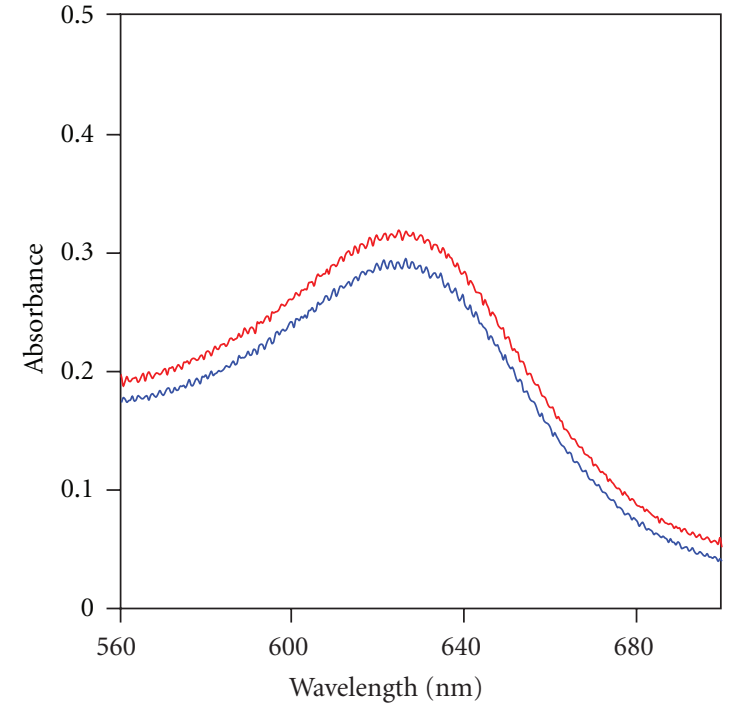

Figure 2: The decreases of absorbance of BCG in the Sephadex LH20 phase in the presence of of MT (1-mm cell, similarly packed with Sephadex LH-20 equilibrated with water as reference). [BCG] = $10^{-4} \mathrm{M} ; 70 \mathrm{mg}$ Sephadex LH-20; from up to down $[\mathrm{MT}]=0.0$ and $1.26 \mu \mathrm{g} \mathrm{mL}^{-1}$.

containing all the reagents except MT was prepared and treated in the same way as the sample. The absorbance (really attenuation) of Sephadex LH-20 gel was measured at $625 \mathrm{~nm}$ (corresponding to the absorption maximum of the BCG) and $800 \mathrm{~nm}$ (the latter is in the $700-850 \mathrm{~nm}$ range, where only the gel "absorbs" light) and compared with a $1 \mathrm{~mm}$ cell packed with gel equilibrated with blank solution. The absorbance difference between sample and blank provides an estimation of the net absorbance.

Wastewater sample containing MT was appropriately diluted with water to get the required concentration, and then the general procedure was followed. The amount of MT was calculated from a calibration graph.

\section{Results and Discussion}

3.1. Absorption Spectra. The BCG color reagent $\left(\mathrm{pK}_{\mathrm{a}}=4.66\right)$ occurs in two acid-base forms in weakly acidic aqueous solutions with the absorption maximum at $430 \mathrm{~nm}\left(\mathrm{BCGH}^{-}\right.$ form) and $615 \mathrm{~nm}\left(\mathrm{BCG}^{2-}\right)$ [16]. When this triarylmethane dye forms ion-pair with $\mathrm{MTH}^{+}\left(\mathrm{pK}_{\mathrm{a}}=5.05\right.$ [1]) in citrate buffer solution at $\mathrm{pH} 4.0$, it is not adsorbed on Sephadex LH20 gel. Therefore, the absorbance difference between solid phase prepared in the absence and in the presence of MT is proportional to MT concentration in solution (Figure 2).

\subsection{Optimization of Conditions}

3.2.1. $\mathrm{pH}$ Dependence. Optimum $\mathrm{pH}$ for the formation of ion-pair and fixation of BCG on Sephadex LH-20 falls below 4.0 (Figure 3). At $\mathrm{pH}$ values of above 4.0 the net absorbance of the solid phase increased due to a decrease in the formation of ion-pair. In $\mathrm{pH}$ 3.0, the monoanionic form 


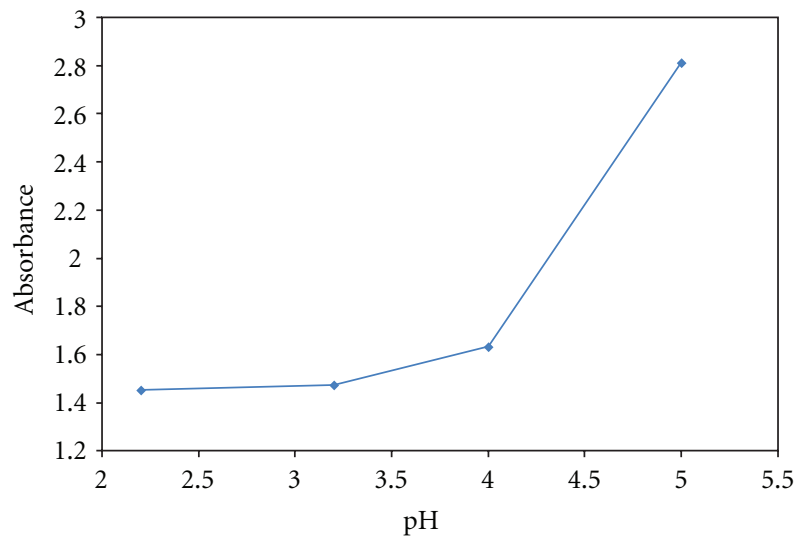

FIGURE 3: Influence of $\mathrm{pH}$ on the absorbance of BCG in solid phase. Conditions: $1.26 \mu \mathrm{g} \mathrm{mL}^{-1}$ of MT; $[\mathrm{BCG}]=10^{-4} \mathrm{M}$; $70 \mathrm{mg}$ Sephadex LH-20; sample volume $10 \mathrm{~mL}$ (air as reference).

TABLE 1: Analytical parameters.

\begin{tabular}{|c|c|}
\hline Intercept & 0.001 \\
\hline Slope $\left(\mathrm{mL} \mu \mathrm{g}^{-1}\right)$ & 0.164 \\
\hline Linear dynamic range $\left(\mu \mathrm{g} \mathrm{mL}^{-1}\right)$ & $0.42-1.68$ \\
\hline Correlation coefficient & 0.9984 \\
\hline $\operatorname{RSD}(\%)$ & 0.03 \\
\hline Detection limit $\left(\mu \mathrm{g} \mathrm{mL}^{-1}\right)$ & 0.05 \\
\hline$\Delta \mathrm{A}$ for sample & $0.082 \pm 0.002^{\mathrm{a}}$ \\
\hline
\end{tabular}

average of three determinations.

of BCG is predominant and then solid phase is yellow with the absorption maximum at $435 \mathrm{~nm}$ but the solid phase is green in $\mathrm{pH} 4.0$ with the absorption maximum at $625 \mathrm{~nm}$. We chose $\mathrm{pH} 4.0$ as the optimum $\mathrm{pH}$ value for the procedure because the absorbance of solid phase was further from UV region. The best of the buffer systems examined was citric acid-citrate $(\mathrm{pH}=4)$.

3.2.2. Other Experimental Conditions. The optimum stirring time before and after adding of Sephadex LH-20 was $4 \mathrm{~min}$ and $5 \mathrm{~min}$, respectively (Figure 4). The fixed BCG is stable for at least 80 min after equilibration (Figure 5). Reproducibility of the method is improved if the cells packed with the solid phase are centrifuged before spectrophotometric measurements are taken. The centrifugation time used here was $1 \mathrm{~min}$ at $2500 \mathrm{rpm}$. Amounts of Sephadex LH-20 of between 25 and $100 \mathrm{mg}$ allow adequate working conditions. A decrease in the amount can result in operational difficulties. For all measurements $70 \mathrm{mg}$ of Sephadex LH-20 was used as a compromise between maximum sensitivity and ease of operation.

3.3. Analytical Data. The calibration graph is reasonably linear for the concentration ranges $0.42-1.68 \mu \mathrm{g} \mathrm{mL}^{-1}$ of MT for the $10 \mathrm{~mL}$ sample system. The analytical parameters are shown in Table 1.

TABLE 2: Comparison of sensitivity of some methods for the determination of methenamine.

\begin{tabular}{lcc}
\hline Method & $\begin{array}{c}\text { Molar absorptivity } \\
\left(\mathrm{L} \cdot \mathrm{mol}^{-1} \cdot \mathrm{cm}^{-1}\right)\end{array}$ & Reference \\
\hline Hantzsch esters formation & $3.8 \times 10^{3}$ & {$[9]$} \\
Complex of MT with iodine & $2.0 \times 10^{4}$ & {$[10]$} \\
FerroZine method & $3.2 \times 10^{4}$ & {$[11]$} \\
Proposed method (SPS) & $2.3 \times 10^{5}$ & This work \\
\hline
\end{tabular}

TABLE 3: Effect of formaldehyde on the determination of $1.26 \mu \mathrm{g} \mathrm{mL}^{-1}$ of methenamine.

\begin{tabular}{lc}
\hline Content $\left(\mu \mathrm{g} \mathrm{mL}^{-1}\right)$ & Absorbance of solid phase \\
\hline 0 & 1.680 \\
3.2 & 1.680 \\
6.4 & 1.680 \\
\hline
\end{tabular}

${ }^{\mathrm{a}}$ Air as reference.

TABLE 4: Determination of methenamine in industrial wastewater sample.

Obtained content of MT by SPS after dilution (10000 times) $\left(\mu \mathrm{g} \mathrm{mL}^{-1}\right)$

\begin{tabular}{ll}
\hline $0.50 \pm 0.01^{\mathrm{b}}$ & $5.61 \pm 0.50^{\mathrm{b}}$ \\
${ }^{\mathrm{a}}$ Reference $[5],{ }^{\mathrm{b}}$ average of three determinations. &
\end{tabular}

Reproducibility was measured for a series of four independent determinations containing $1.26 \mu \mathrm{g} \mathrm{mL}^{-1}$ of MT and was $0.03 \%$.

The sensitivity, expressed as molar absorptivity, of the proposed method is compared in Table 2 with those of published spectrophotometric methods. The higher sensitivity of the proposed method is apparent.

3.4. Interference. Methenamine wastewater that is formed in the production of MT usually contains residual amounts of MT and formaldehyde. It has been reported that formaldehyde is the most serious interference in the determination of MT $[6,11]$. Formaldehyde does not interfere in the determination of MT by proposed method (Table 3 ) because it is a neutral molecule and does not form ion-pair with BCG.

3.5. Determination of MT in Industrial Wastewater Sample. The method was applied to the determination of MT in wastewater sample by calibration curve method ( $\Delta \mathrm{A}$ versus concentration of MT). To check the accuracy of the proposed method, conductometric method [5] was also applied for determination of MT in the wastewater. The results obtained, summarized in Table 4, confirm each other. It should be noted that this analytical method can be used for other 


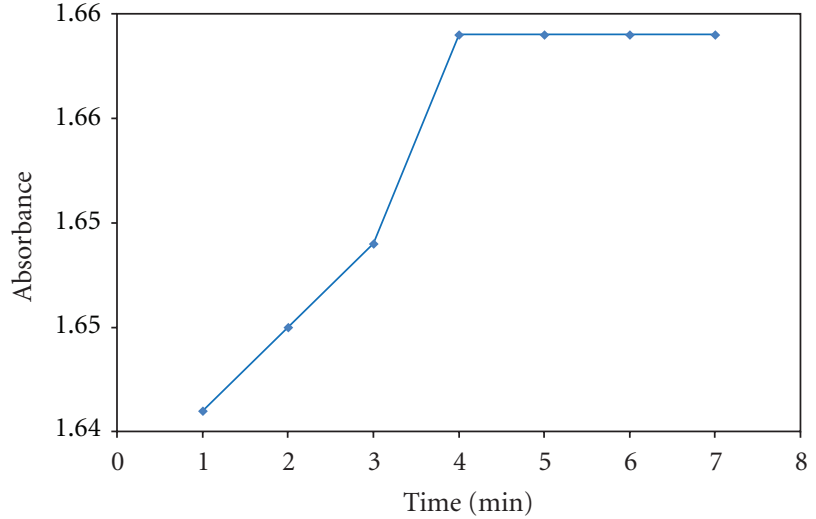

(a)

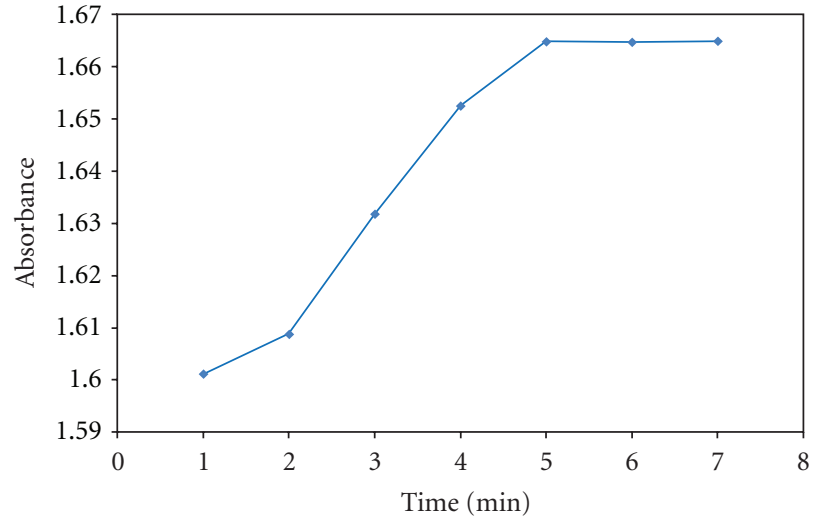

(b)

FIgURE 4: Influence of stirring time on the absorbance of BCG in solid phase. Conditions: $1.26 \mu \mathrm{g} \mathrm{mL}^{-1} \mathrm{of} \mathrm{MT;}[\mathrm{BCG}]=10^{-4} \mathrm{M} ; \mathrm{pH}=4.0$; $70 \mathrm{mg}$ Sephadex LH-20; sample volume $10 \mathrm{~mL}$ (air as reference). (a) Before the adding of Sephadex LH-20; (b) after the adding of Sephadex LH-20.

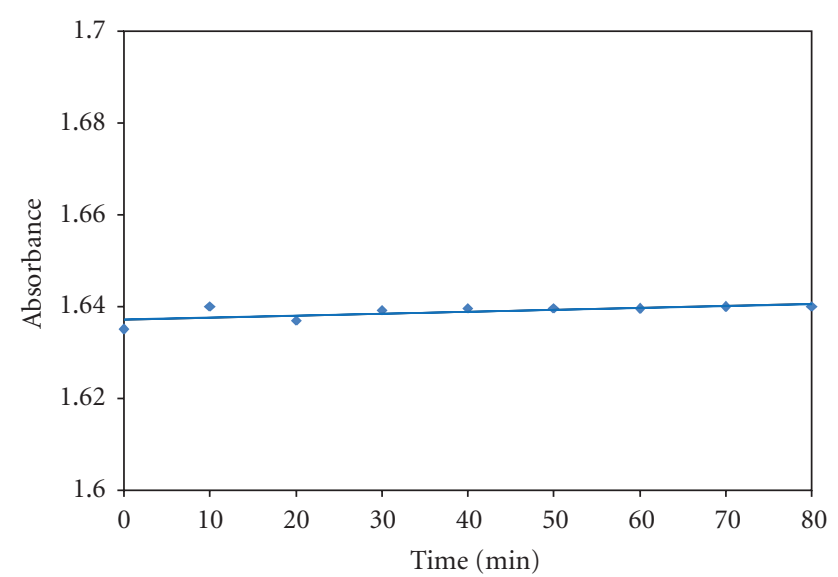

FIGURE 5: Stability of absorbance of BCG in solid phase on duration time. Conditions: $1.26 \mu \mathrm{g} \mathrm{mL}^{-1}$ of MT; $[B C G]=10^{-4} \mathrm{M}$; $\mathrm{pH}=4.0$; $70 \mathrm{mg}$ Sephadex LH-20; stirring time $5 \mathrm{~min}$; sample volume $10 \mathrm{~mL}$ (air as reference).

wastewaters containing MT provided that other constituents of wastewater do not form ion-pair with BCG.

\section{Conclusions}

Methenamine at the microgram level can be determined efficiently with BCG using the solid phase spectrophotometry technique without expensive apparatus. The proposed method has been applied to the determination of MT in industrial wastewater sample with good result. The method is simple and more sensitive as compared to others commonly used at the microgram level. The method does not use organic solvents, extra organic compounds as reactants, and pretreatment of the sample. Therefore, the method is environmentally friendly and can be considered as a green analytical method. It has been demonstrated that formaldehyde does not interfere in the determination of MT by proposed method.

\section{Acknowledgments}

The authors express their appreciation to Sina Chemical Industries Company and Payame Noor University for supporting this study.

\section{References}

[1] G. Strom Jr. and H. W. Jun, "Separation and quantitation of methenamine in urine by ion-pair extraction," Journal of Pharmaceutical Sciences, vol. 75, no. 4, pp. 416-420, 1986.

[2] J. M. Dreyfors, S. B. Jones, and Y. Sayed, "Hexamethylenetetramine: a review," American Industrial Hygiene Association Journal, vol. 50, no. 11, pp. 579-585, 1989.

[3] A. Alamdari and F. Tabkhi, "Kinetics of hexamine crystallization in industrial scale," Chemical Engineering and Processing, vol. 43, no. 7, pp. 803-810, 2004.

[4] F. Meissner, E. Schwiedessen, and D. F. Othmer, "Continuous production of hexamethylenetetramine," Industrial \& Engineering Chemistry, vol. 46, no. 4, pp. 724-727, 1954.

[5] N. Saadatjou, M. Taghdiri, and R. Farrokhi, "Removal of urotropine from industrial wastewater by acidic cation exchange resins," Iranian Journal of Environmental Health Science and Engineering, vol. 7, no. 4, pp. 345-352, 2010.

[6] G. L. Madsen, D. S. Crumrine, and B. Jaselskis, "Proton nuclear magnetic resonance determination of hexamethylenetetramine in the presence of formaldehyde and urine," Analyst, vol. 121, no. 4, pp. 567-570, 1996.

[7] M. Koga, R. Shinohara, and T. Akiyama, "Gas chromatographic determination of trace amounts of hexamethylenetetramine in water using an iodine charge-transfer complex," Analytical Sciences, vol. 1, no. 4, pp. 381-384, 1985.

[8] C. Pavitrapok and D. A. Williams, "Determination of methenamine, methenamine mandelate and methenamine hippurate in pharmaceutical preparations using ion-exchange HPLC," Journal of Pharmaceutical and Biomedical Analysis, vol. 40, no. 5, pp. 1243-1248, 2006.

[9] M. Balasubramanian, S. Thennarasu, T. Sudhakaran, and P. T. Perumal, "Spectrophotometric and fluorimetric determination of hexamine in pure form and its pharmaceutical 
formulation," Biological and Pharmaceutical Bulletin, vol. 26, no. 8, pp. 1211-1214, 2003.

[10] A. M. Taha, N. A. El-Rabbat, and F. A. Fattah, "Spectrophotometric assay of hexamethylenetetramine," The Analyst, vol. 105, no. 1251, pp. 568-574, 1980.

[11] G. L. Madsen and B. Jaselskis, "Spectrophotometric determination of hexamethylenetetramine," Analyst, vol. 117, no. 11, pp. 1785-1788, 1992.

[12] J. K. Lim and C. C. C. Chen, "Spectrophotometric determination of methenamine and its salts by 2-hydrazinobenzothiazole," Journal of Pharmaceutical Sciences, vol. 62, no. 9, pp. 1503-1504, 1973.

[13] E. Sawicki, T. R. Hauser, and S. McPherson, "Spectrophotometric determination of formaldehyde and formaldehydereleasing compounds with chromotropic acid, 6-amino-1naphthol-3-sulfonic acid (J Acid), and 6-anilino-1-naphthol3-sulfonic acid (Phenyl J Acid)," Analytical Chemistry, vol. 34, no. 11, pp. 1460-1464, 1962.

[14] S. Matsuoka and K. Yoshimura, "Recent trends in solid phase spectrometry: 2003-2009. A Review," Analytica Chimica Acta, vol. 664, no. 1, pp. 1-18, 2010.

[15] M. Taghdiri and A. Mohamadipour-Taziyan, "Application of sephadex LH-20 for microdetermination of dopamine by solid phase spectrophotometry," ISRN Pharmaceutics, vol. 2012, Article ID 216068, 5 pages, 2012.

[16] N. Silva and E. E. S. Schapoval, "Spectrophotometric determination of etidocaine in pharmaceutical (dental) formulation," Journal of Pharmaceutical and Biomedical Analysis, vol. 29, no. 4, pp. 749-754, 2002. 


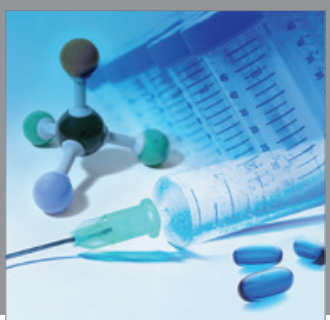

International Journal of

Medicinal Chemistry

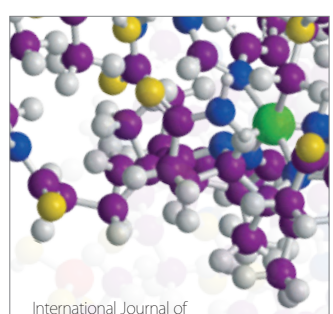

Carbohydrate Chemistry

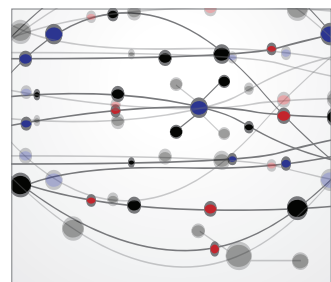

The Scientific World Journal
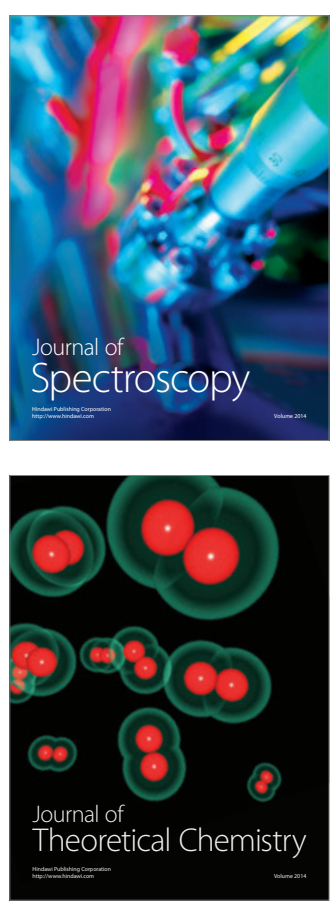
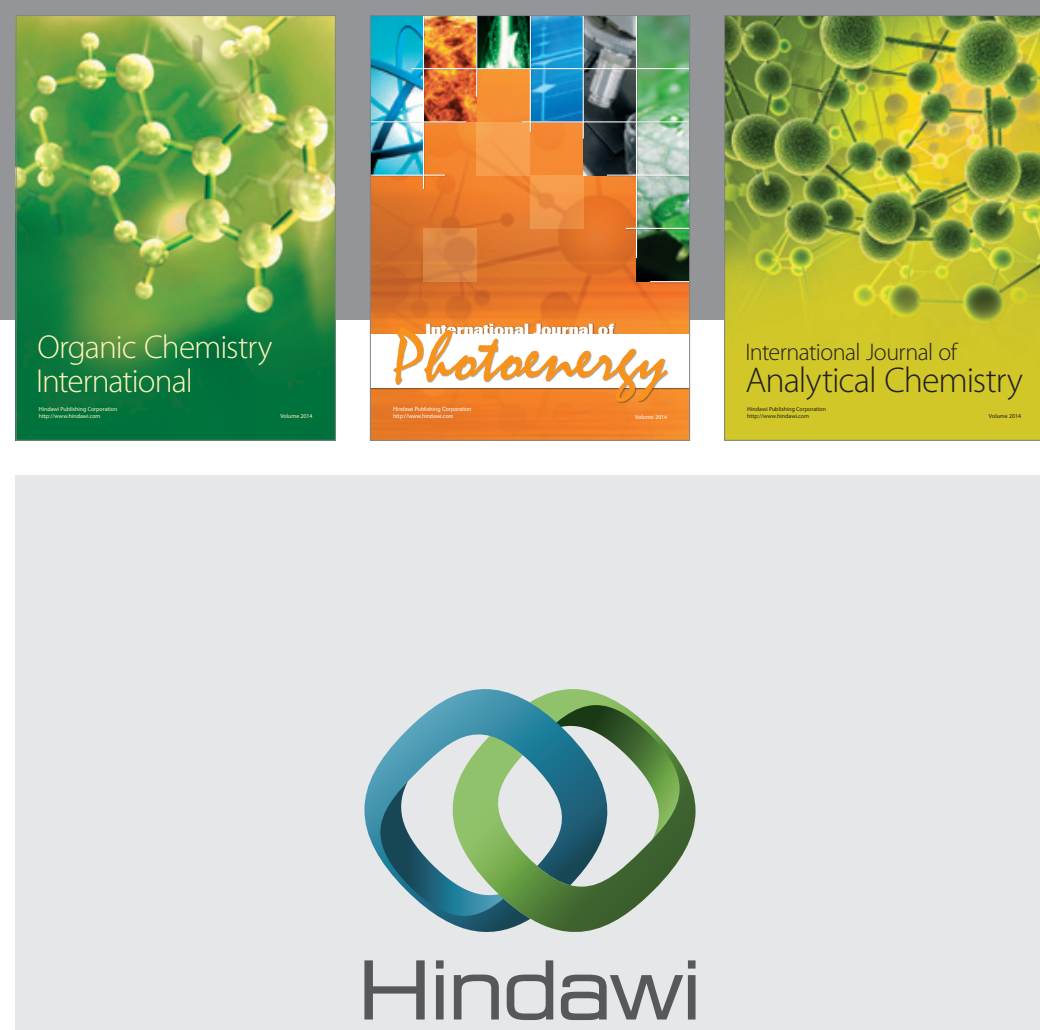

Submit your manuscripts at

http://www.hindawi.com
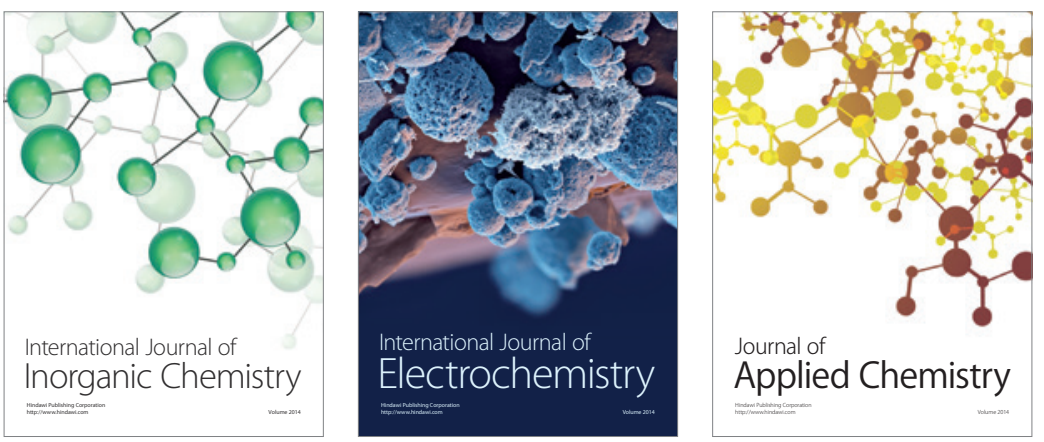

Journal of

Applied Chemistry
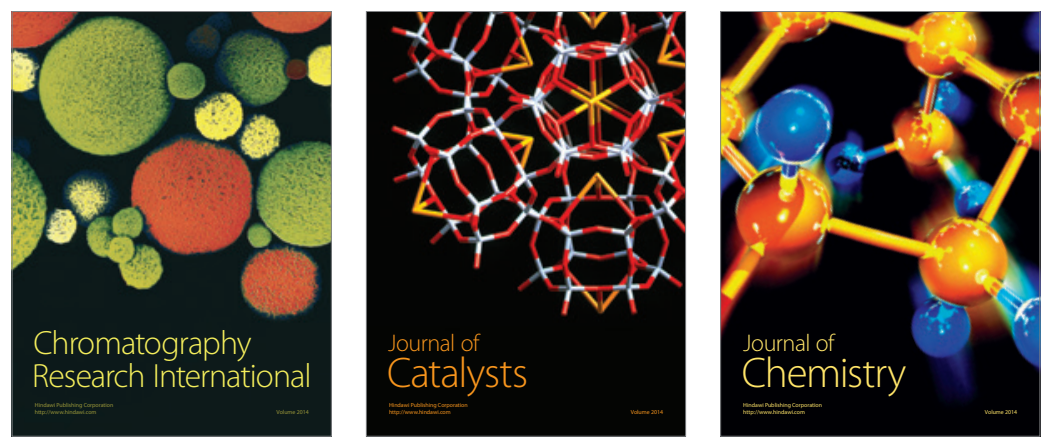
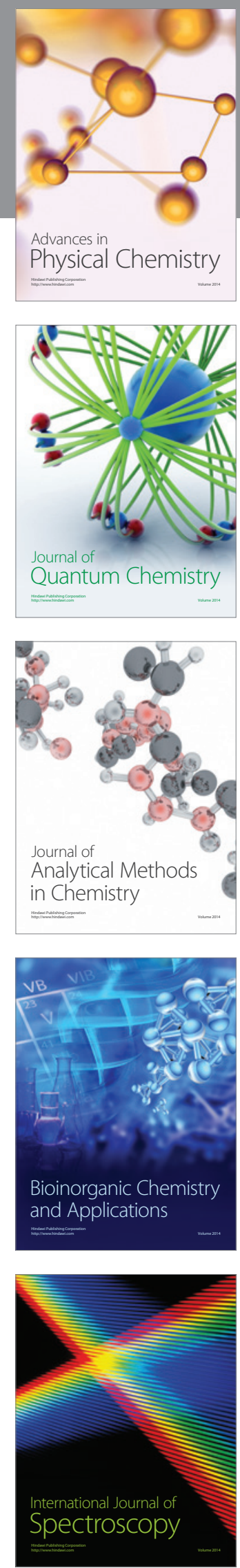